\title{
Labor Productivity and Wages in Rural and Urban Manufacturing Plants
}

H. Frederick Gale, Jr.*

\begin{abstract}
Plant-level data from the 1993 Survey of Manufacturing Technology matched with the Census of Manufactures are employed to explore rural-urban patterns of production worker wages and productivity. Rural-urban wage differentials diminish, but are still significant, when productivity, plant, and location characteristics are controlled for. Differences in the nonproduction worker share, schooling, and a compensating differential for housing costs appear to make important contributions to the rural-urban wage differential.
\end{abstract}

\section{INTRODUCTION}

Data from Bureau of Economic Analysis show a rural-urban gap in nonfarm earnings per worker of 27 percent in 1993 (U.S. Department of Agriculture 1996, p. 57). Recent studies by Glaeser and Maré (1994), Bernat (1994), and Gale (1997) found rural-urban wage differentials of similar magnitude. Studies have also found a rural-urban differential in worker productivity (Bernat 1995; Carlino 1978; Ciccone and Hall 1996; Martin, McHugh, and Johnson 1993; and other studies reviewed by Moomaw 1983). Profit maximization suggests that worker productivity is a primary determinant of worker earnings, but few studies have investigated the parallel relationship between rural-urban differences in wages and worker productivity. Do productivity differences explain the rural-urban wage differential? What location characteristics affect spatial differences in wages? What types of plants pay higher wages?

In this study I investigate the effects of rural-urban location on wages and worker productivity using a large sample of manufacturing plants. The use of plant-level data allows me to investigate whether rural-urban differences persist when I control for productivity, plant, and location characteristics. Including these controls in the model reduces, but does not eliminate, the rural-urban differential in wages. The use of plant-level data also overcomes aggregation problems associated with county- or SMSA-level data used by many previous studies (Greytak and Blackley 1985). This study disaggregates the labor input into production and nonproduction labor. Recent research has noted a shift toward nonproduction labor in manufacturing, which is an indicator of skill upgrading (Berman, Bound and Griliches 1994; Doms, Dunne and Troske 1997). Urban plants use a higher proportion of nonproduction labor than do rural plants (Gale 1997), so this distinction may be important in making rural-urban productivity comparisons. The sample represents all regions and five major (two-digit) manufacturing industries 
(accounting for 40 percent of manufacturing employment), which gives the results generality.

\section{THE MODEL}

This section develops an empirical model that will be used to estimate the rural-urban wage differential while controlling for worker productivity, other plant characteristics, and location characteristics. The neoclassical approach considers worker productivity to be the primary determinant of the demand for labor, and, consequently, of wages when markets are competitive. Typically, manufacturing plant $\mathrm{j}$ at location $\mathrm{k}$ has output, $\mathrm{Q}_{\mathrm{j} \mathrm{k}}$, determined by a production function,

$$
\mathrm{Q}_{\mathrm{jk}}=\mathrm{f}\left(\mathrm{K}_{\mathrm{j} \mathrm{k},}, \mathrm{LP}_{\mathrm{jk},}, \mathrm{LN}_{\mathrm{jk}} ; \mathrm{T}_{\mathrm{jk},}, \mathrm{X}_{\mathrm{jk},}, \mathrm{Z}_{\mathrm{k}}\right) \text {, }
$$

where $\mathrm{K}_{\mathrm{jk}}$ represents capital, $\mathrm{LP}_{\mathrm{jk}}$ is production worker labor, $\mathrm{LN}_{\mathrm{jk}}$ is nonproduction worker labor, $T_{j k}$ is the level of technology use in the plant, $X_{j k}$ represents other plant characteristics that affect productivity, such as plant ownership and age, and $Z_{k}$ represents characteristics of the plant's location $k$, such as urbanization or labor force quality. Most previous work aggregated nonproduction and production workers into a single labor input, but this study considers the two as separate inputs. Nonproduction workers include personnel in management, sales, delivery, technical, accounting, and other "overhead" operations. Production workers are those directly involved in production, including line-level supervisors. This study focuses on production worker hours as the labor input. Under profit maximization for competitive firms, the demand for labor is determined by the marginal condition, $\mathrm{w}_{\mathrm{LP}}=\mathrm{P}\left(\mathrm{MP}_{\mathrm{LP}}\right)$, where $\mathrm{w}_{\mathrm{LP}}$ represents the wage offered by the plant, $\mathrm{P}$ is the price of the firm's output, and $\mathrm{MP}_{\mathrm{LP}}$ is the marginal product of production worker labor. ${ }^{1}$

The average product of labor is more easily observed than the marginal product, and consequently many discussions of worker productivity use output per worker. This simplification is reasonable when marginal product is proportional to average product with homogeneity of degree one in the production function, as is the case in the oft-used Cobb-Douglas production function. Then the wage can be expressed as a function of the average product of production labor, $\mathrm{AP}_{\mathrm{LP}}$ :

$$
\mathrm{w}_{\mathrm{LP}}=\mathrm{P} \propto \mathrm{AP}_{\mathrm{LP}}
$$

A Cobb-Douglas per-unit-of-labor production function similar to that of Griliches and Ringstad (1971) with homogeneity of degree one is used to express average product of labor as a function of input ratios, technology, and other characteristics,

$$
\mathrm{AP}_{\mathrm{LP}}=\alpha\left(1-\beta_{1}-\beta_{2}\right)\left(\frac{\mathrm{K}}{\mathrm{LP}}\right)^{\beta_{1}}\left(\frac{\mathrm{LN}}{\mathrm{LP}}\right)^{\beta_{2}} \mathrm{e}^{\beta_{3} \mathrm{~T}+\beta_{4} \mathrm{X}+\beta_{5} Z},
$$

where $\beta \mathrm{i}$ are parameters of the Cobb-Douglas production function. For this sim- 
ple analysis I assume that $\mathrm{T}, \mathrm{X}$, and $\mathrm{Z}$ only affect the intercept of the production function, and not the parameters $\beta_{1}$ and $\beta_{2}$.

Using an equation based on (3) in logs, I estimate the productivity and wage equations as a recursive system:

$$
\begin{aligned}
& \ln w_{\mathrm{LP}}=\gamma_{0}+\gamma_{1} \ln \mathrm{P}_{\mathrm{LP}}+\gamma_{\mathrm{P}} \mathrm{PLANT}+\mathrm{v} \\
& \ln \mathrm{P}_{\mathrm{LP}}=\Theta_{0}+\theta_{1} \ln \left(\frac{\mathrm{LN}}{\mathrm{LP}}\right)+\Theta_{2} \ln \left(\frac{\mathrm{K}}{\mathrm{LP}}\right)+\Theta_{\mathrm{P}} \mathrm{PLANT}+\Theta_{\mathrm{L}} \mathrm{LOCATION}+\mathrm{u}
\end{aligned}
$$

where PLANT and LOCATION are characteristics of the plant and location, respectively, and $v$ and $u$ are stochastic error terms. Estimates of $\gamma_{P}, \gamma_{L}, \Theta_{P}$, and $\Theta_{L}$, indicate the effects of plant characteristics directly on wages and indirectly through their effect on productivity. I estimate (5) for each of 39 industries represented in the data to permit production technology to vary by industry. I use the predicted value from equation (5) as the measure of productivity to estimate the wage equation (4). Plant and location characteristics included on the right-hand side of (5) may affect the average wage paid by a plant through their effect on productivity. The wage equation (4) also includes some of these characteristics to allow them to have an effect on wages independent of their productivity effect. Many studies have found that plant and firm size are positively associated with wages (Brown and Medoff 1989). Doms, Dunne and Troske (1997) find that technology use is associated with higher wages. Local schooling and labor force age are also included to determine whether these variables have effects on wages that are not captured by their effects on productivity. Plant age may also have an effect on wages. Older plants may have workers with longer tenure and more experience, both of which are associated with higher wages. Differences in profitability between old and new plants, due to capital vintage or other reasons, could also affect wages. Location characteristics include local industry size, labor force characteristics, and cost of living measures. Localization of industry could be associated with higher wages, due to the accumulation of industry-specific skills in the local labor force or relatively strong local demand for workers. The racial mix of the plant's local area may also affect wages. Plants in minority-dominated areas may pay lower wages due to discrimination or labor market imperfections. A housing cost variable is included to test for the possibility that higher urban wages represent a compensating differential for higher cost of living in urban areas.

Rural-urban location is one of the characteristics included in the vector of location characteristics that influence productivity and wages. A number of studies have investigated the effect of urban location on productivity (see the review by Moomaw 1983). Two agglomeration effects are specified in most studies. A general urbanization effect on productivity due to larger city size, which increases availability of infrastructure, producer services, and information, is measured by the population or total employment in the area. Localization of an industry (concentration of related firms in the same industry at a particular location) develops a pool of specialized labor and services and facilitates diffusion of industry-specific information and innovations. Characteristics of the local labor force, including 
schooling and age of workers, could also affect productivity.

Rural-urban differences in wages are estimated by including dummy variables based on modified Beale code categories in the wage equation. Previous studies have often used a continuous population variable or a metro-nonmetro dummy variable as a rural-urban measure. Table 1 shows how the 10 Beale codes were collapsed into 7 codes to simplify the analysis and to accommodate the relatively few observations (about 100 each) in codes 8 and 9. About half of the SMT plants were in the Core Metro (B0) category (Table 2). The most rural category is Rural Nonadjacent (B5), followed by Rural Adjacent (B6), the excluded category. The set of dummies used here can capture differences within metro and nonmetro county types. For example, wages in Urbanized Nonmetro (B4) counties may be more similar to metro counties (B0, B1, B2, B3) than they are to wages in more rural (B5 and B6) nonmetro counties. The set of dummies can also capture nonlinear rural-urban effects. For example, wages may be highest in Small Metro (B3) counties.

TABLE 1

Rural-urban codes as related to ERS rural-urban continuum

\begin{tabular}{cll}
\hline ERS code & Description & Study Variable \\
\hline 0 & Central counties of metro areas of 1 mil or more & B0: Large metro-core \\
1 & Fringe counties of metro areas of 1 mil or more & B1: Large metro-fringe \\
2 & Metro areas 250,000-1 mil population & B2: Medium metro \\
3 & Metro areas under 250,000 population & B3: Small metro \\
4 & Nonmetro, urban pop 20,000+, adjacent to metro & B4: Urbanized nonmetro \\
5 & Nonmetro, urban pop 20,000+, not adjacent & \\
6 & Nonmetro, urban pop 2,500-20,000, adjacent & B5: Rural adjacent \\
8 & Nonmetro, urban pop <2,500, adjacent & B6: Rural nonadjacent \\
7 & Nonmetro, urban pop 2,500-20,000, not adjacent & \\
9 & Nonmetro, urban pop <2,500, not adjacent &
\end{tabular}

ERS codes based on Butler (1990)

TABLE 2

Descriptive statistics by modified Beale code

\begin{tabular}{lccccc}
\hline Beale code & $\mathrm{N}$ & $\begin{array}{c}\text { VA/hour } \\
\text { dollars }\end{array}$ & $\begin{array}{c}\text { Wage/hour } \\
\text { dollars }\end{array}$ & $\begin{array}{c}\text { Machinery/hr. NPW share } \\
\text { dollars }\end{array}$ & $\begin{array}{c}\text { percent } \\
\text { B0: Large metro - core }\end{array}$ \\
\hline 3,567 & 52.51 & 11.73 & 10.61 & 38.3 \\
B1: Large metro - fringe & 262 & 46.92 & 10.99 & 13.01 & 32.8 \\
B2: Medium metro & 1,525 & 45.86 & 11.42 & 12.31 & 32.8 \\
B3: Small metro & 569 & 42.08 & 10.84 & 12.61 & 30.7 \\
B4: Urbanized nonmetro & 479 & 40.83 & 10.81 & 13.18 & 28.0 \\
B5: Rural nonmetro - adjacent & 480 & 36.71 & 9.94 & 9.76 & 24.9 \\
B6: Rural nonmetro - nonadjacent & 393 & 33.50 & 9.40 & 9.10 & 23.9 \\
\hline
\end{tabular}

$\mathrm{VA}=$ value added, hour=production worker hours, Wage=production worker hourly wage, Machinery=value of machinery, beg. of yr. NPW share=nonproduction worker share of total employment. Statistics are weighted for sample stratification.

Source: 1993 Survey of Manufacturing Technology matched with 1992 Census of Manufactures.

Three hypotheses are tested. (1) No metro-nonmetro effects $(B 0=B 1=B 2=B 3=B 4=B 5=0$, no rural-urban differences in wages). (2) All metro types and urbanized nonmetro are equal $(B 0=B 1=B 2=B 3=B 4$. Wages in urbanized nonmetro counties are equal to those in metro counties). (3) All metro types are equal $(B 0=B 1=B 2=B 3$, no wage differences among metro areas of different sizes). 
The hypotheses are tested first in an equation which includes only industry dummies as controls. The hypotheses are then tested in the full model that includes productivity, plant, and location characteristics. Comparison of the results will indicate the nature and magnitude of the rural-urban wage differential and whether the differential can be accounted for by productivity, plant, and location characteristics.

\section{DATA}

The data are plant-level observations from the Census Bureau's 1993 Survey of Manufacturing Technology (SMT), which collected information on technology use and other plant characteristics from a sample of over 8,000 manufacturing establishments with 10 or more employees in five broad industry groups: Fabricated Metal Products, Industrial Machinery and Equipment, Electrical Equipment, Transportation Equipment, and Instruments (SIC 34-38). The SMT data were matched with records from the 1992 Census of Manufactures (COM) to add information about plant wages, input use, and productivity. Approximately 7,000 observations have usable data on all variables. Plants of different sizes were sampled at different rates for the SMT. Sample weights recommended by Cochrane were employed to improve efficiency of the regression estimates. ${ }^{2}$

Wages are represented by average hourly wages of production workers. Manufacturing value added per production worker hour from the 1992 COM represents average product of production labor. Value added is the difference between the final value of goods shipped from manufacturing plants minus the cost of materials and parts used to produce the goods. An appendix to this article addresses the criticism of value added as a measure of productivity due to its exclusion of purchased services.

Capital is measured by the book value of machinery and equipment reported in the COM. ${ }^{3}$ Data on building values were excluded from the capital measure due to the poor quality of the data, frequency of missing values, and rural vs. urban bias in real estate values. The capital-labor ratio is represented by the ratio of machinery value per production worker hour. The ratio of nonproduction to production worker labor is represented by nonproduction workers per production worker hour. Technology is represented by the number of advanced technologies used in the plant. The SMT asked respondents to report whether or not they used each of 17 different technologies (U.S. Bureau of the Census 1994). The average number of technologies was about 3.5. Twenty-three percent of plants reported 0 technologies, and five percent reported ten or more. A dummy variable equal to 1 for plants in multiunit firms (a measure of firm size), and a set of dummy variables representing plant age are also included. The log of plant employment is a measure of establishment size. Differences in intercepts across industries are captured by dummy variables corresponding to three-digit SIC codes.

${ }^{2}$ The weights are $1 /(1-\mathrm{fh}) \frac{1}{2}$, where fh is the probability of a unit from strata $\mathrm{h}$ being included in the sample (Barkley, Dahlgren, and Smith, 1988; Cochrane, 1978). The fh values were computed by the Census Bureau.

${ }^{3}$ Martin, McHugh and Johnson (1993), p. 466, discuss the shortcomings of this measure, which they also employed. 
The wage equation uses county Beale code dummies (Butler 1990) as the urbanization measure. Urbanization is represented in the production function estimates by the log of commuting zone population. Commuting zones are aggregations of contiguous counties based on commuting patterns that define geographic labor markets (Tolbert and Sizer 1996). In preliminary production function estimates few of the county Beale code dummy variables were significantly different from zero. The estimates presented here use the log of population as the urbanization measure in order to reduce the number of coefficients reported. Local industry size is represented by the number of establishments in the plant's two-digit industry located in its commuting zone, as reported in the 1992 COM.

Labor force characteristics are estimated from 1990 Census of Population. Average years of schooling by persons of prime working ages (25-44) in 1990 in the plant's commuting zone is a measure of education. ${ }^{4}$ The percent of working age adults (ages 18-64) over age 55 in the commuting zone is a measure of work force age, which may represent vintage of worker skills. Percent of population in the plant's county that is nonwhite represents the racial makeup of the plant's local area. The minority percent variable is on a county basis because concentrations of minority population in a particular county can be hidden by commuting zone averages. Housing costs are represented by the average rent for a twobedroom housing unit. ${ }^{5}$

\section{RESULTS}

Table 2 shows mean productivity, wages, capital-labor and nonproductionproduction labor ratios by degree of urbanization. Productivity and wages clearly fall as plant location becomes more rural. The average production worker wage is highest in large metro plants, at $\$ 11.73$ per hour. This is about 25 percent higher than the average in rural nonmetro counties not adjacent to a metro area. The second-highest wages are in medium metro counties, with an average of $\$ 11.42$. Wages at plants in large metro-fringe counties, small metro areas, and urbanized nonmetro areas are similar, in the range of $\$ 10.81-10.99$. While wages in urbanized nonmetro counties are similar to wages in metro plants, wages are lower in the more rural nonmetro categories. The average is $\$ 9.94$ in rural counties adjacent to a metro area, and $\$ 9.40$ in rural counties not adjacent to a metro area.

Labor productivity, as measured by value added per hour of production labor, is $\$ 52.51$ in large metro areas, nearly 57 percent higher than the average of $\$ 33.50$ in the most-rural locations. Value added per unit of labor declines steadily as the level of urbanization decreases. Part of the productivity and wage differentials could be due to differences in the mix of industries in rural and urban areas. Gale (1997) found that about half of the differential was due to industry mix, but industry mix is probably less important here because the data are from a more narrow range of industries.

\footnotetext{
${ }^{4}$ Average schooling is estimated by taking a weighted average of the mid-points of the schooling completion classes published by the Census of Population. Other measures, such as percent completing high school, give similar qualitative results.

${ }^{5}$ The housing cost variable is constructed in a manner similar to the schooling variable.
} 
Differences in capital and skilled labor per unit of production labor could also explain the productivity differential. The capital-labor ratio, however, does not show a clear association with urbanization. Value of machinery per labor hour is highest in fringe counties of large metro areas and urbanized nonmetro counties. It is lowest in rural nonmetro counties, but the value in large metro counties is also low. Concentration of skilled labor in urban plants appears to be a better candidate for explaining the rural-urban productivity differential. A clear ruralurban pattern is observed for the nonproduction worker share. An average of 38.3 percent of employees are nonproduction workers in large metro plants. The average falls to 23.9 percent in the most rural plants. The nonproduction-production worker ratio for plants in large metro counties is 60 percent higher than the ratio for the most rural plants. This differential is similar to the 57 percent differential observed for productivity. The clear difference in nonproduction worker share between rural and urban plants and its close association with worker productivity suggests that it is important to disaggregate the labor input into production and nonproduction workers.

Table 3 presents production function estimates for each of 39 three-digit industries. The estimates vary considerably across industries. Only one industry (opthalmic goods, SIC 385) has a positive urbanization effect significantly different from zero. A number of industries have negative coefficients. The lack of urbanization effects contrasts with the means shown in Table 2, which showed a clear association between productivity and urbanization. In Table 3 , only five industries show significant positive localization effects: ordnance (SIC 348), communications equipment (SIC 366), electronic components (SIC 367), ship building and repair (SIC 373), and measuring and controlling devices (SIC 382). Eliminating industry mix effects (estimating the production functions by industry) and controlling for input mix appears to explain most of the urbanization and localization productivity effects in this sample.

Most coefficients on the machinery variable are positive, and twenty-two are significantly different from zero. The significant coefficients range from .05 to .17 , with motor vehicles (SIC 371) having the largest coefficient. The coefficients on the nonproduction worker variable are positive and significantly different from zero for all but two industries. Significant values range from .16 to .64, but most are between .30 and .50. Implied production worker coefficients (assuming homogeneity of degree one) are generally .50 to .60 . The technology variable has a significant positive effect on productivity for eleven industries, but in most industries the coefficient is small and not significantly different from zero. Technology use has the strongest association with productivity for farm and garden machinery (SIC 352) and miscellaneous transportation equipment (SIC 379), and medical instruments (SIC 384). Multiplant status has a significant positive effect for twenty industries. The significant coefficients generally range between .11 and .29. Average schooling has a significant positive effect on productivity in fourteen industries, but the schooling coefficient was negative (although not significantly different from zero) in fifteen industries. Among the industries where 


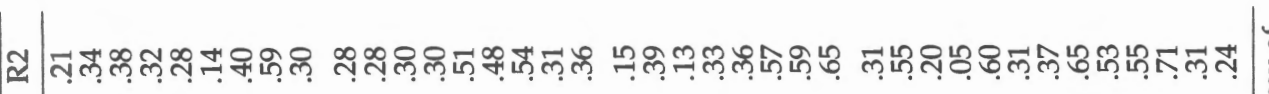

Q

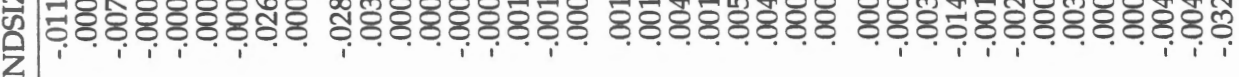

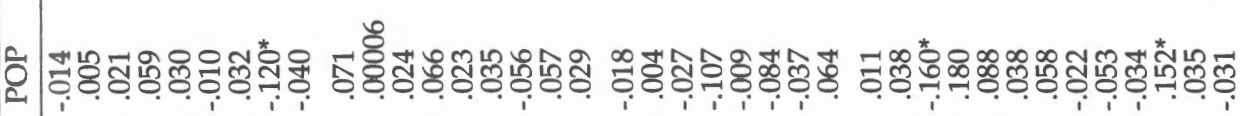

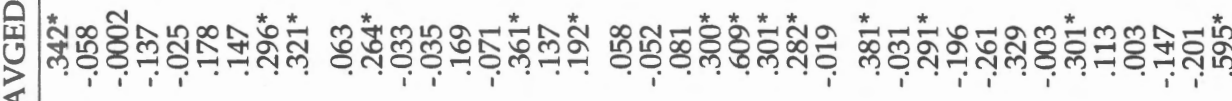

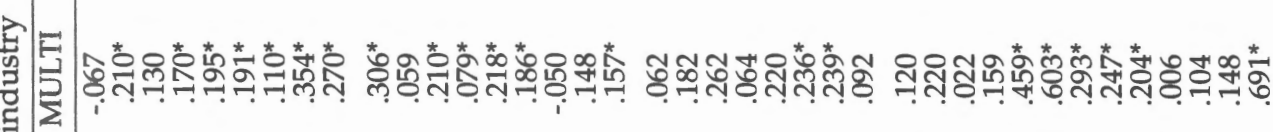
.

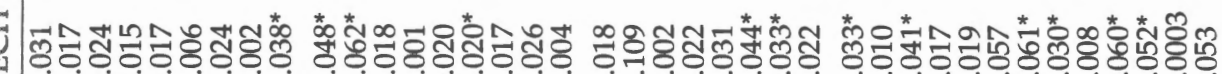

더 巳

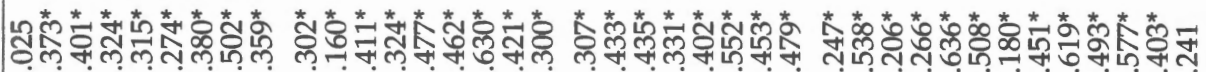

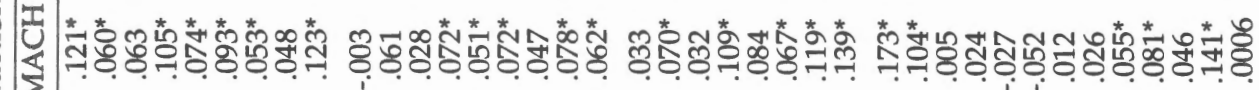

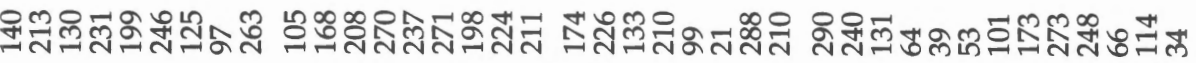

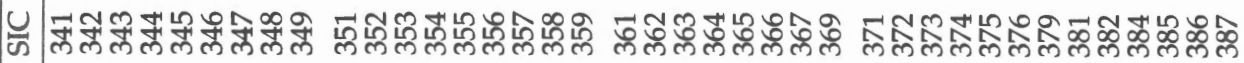

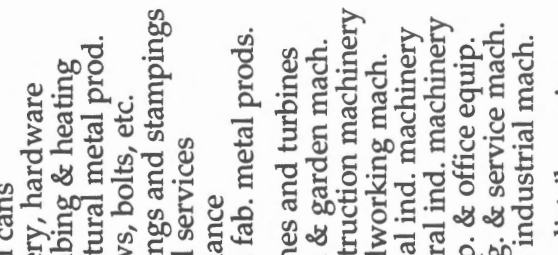

-

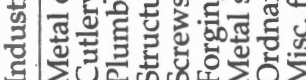

क凶ट

:

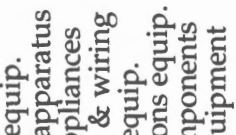
অ. 包司:

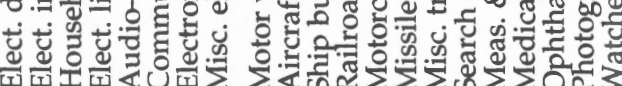

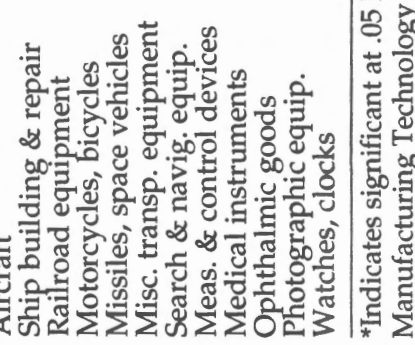


schooling was significant, a one-year increase in average schooling in the plant's area was associated with a 20 to 30 percent higher level of productivity. Labor force age was never significantly different from zero in the production function equations, so this variable is omitted from the table.

Log of hourly production worker wage equations are presented in Table 4. Model 1 shows a specification that includes only the modified Beale code dummies with controls for three-digit industry, while Model 2 shows the results when productivity and other plant and location characteristics are included in the model. In Model 1, all six county types have significantly higher wages than the most rural (nonadjacent) counties. F-tests reject the hypothesis that all county types have equal wages. Plants in large metro-core counties (B0) have wages about 20 percent higher than wages in the most rural plants after controlling for industry. This is slightly less than the 25 percent differential observed in Table 2. The coefficient for rural adjacent counties (B5) suggests that, among rural counties (those with no town larger than 20,000), adjacency to a metro area is associated with a wage premium of about 5 percent. Medium metro (B2) wages are just slightly lower than large metro-core (B0) wages. Plants in small metro (B3), large metro-fringe (B1), and urbanized nonmetro (B4) locations appear to have similar wage levels-about 13 to 14 percent higher than those in the most rural locations. Model 1 explains 12 percent of the variation in wages.

Model 2 adds predicted productivity using industry-level production functions, plant, and location characteristics to the wage equation, which increases explanatory power to 31 percent. Productivity has a positive effect on wages in Model 2, as expected. A doubling of productivity is associated with an increase in the wage of about 18 percent. Multiunit status and technology use have positive effects on wages in addition to their indirect effect via productivity in many industries. Larger and older plants pay higher wages. Brown and Medoff (1989) have offered a number of explanations for plant and firm size effects on wages (multiunit status is likely a proxy for larger firm size). Plant age may be a proxy for employee tenure, experience, or unionization, or it may represent a selection effect, whereby the most successful plants remain in business and have higher pay (i.e., unsuccessful old plants are unobserved). Doms, Dunne and Troske (1997) also found a positive plant age effect on the plant wage. Several location characteristics are also significant. Local industry size and average schooling have positive effects on wages, as does the log of housing cost. Labor force age and minority population do not have statistically significant effects.

When plant and location characteristics enter the equation, rural-urban effects are weaker than in the reduced model, but are still significant. Plants in medium metro (B2) counties have the largest coefficient, indicating a wage premium of 7.7 percent over Rural Nonadjacent counties. The differential for large metro-core (B0), small metro (B3), and urbanized nonmetro (B4) over rural nonadjacent counties is only slightly smaller, in the range of 5 to 7 percent. Large metro-fringe (B1) plants have wages about 4 percent higher, and rural adjacent (B5) plants have wages 3 percent higher than rural nonadjacent counties, but nei- 
ther coefficient is signficiantly different from zero. F-tests reject the hypothesis that all county types have equal wages. We cannot reject the hypothesis that metro county types and urbanized nonmetro counties have equal wages. Neither can we reject the hypothesis of no difference within metro county types. These results suggest a threshold in the urbanization-wage relationship, once the model has accounted for productivity, plant, and location characteristics. For counties with a city or town of at least population 20,000 , there is little or no relationship between wages and the degree of urbanization. However, wages are lower in more rural locations.

\section{TABLE 4}

Wage regressions, all industries, 1992

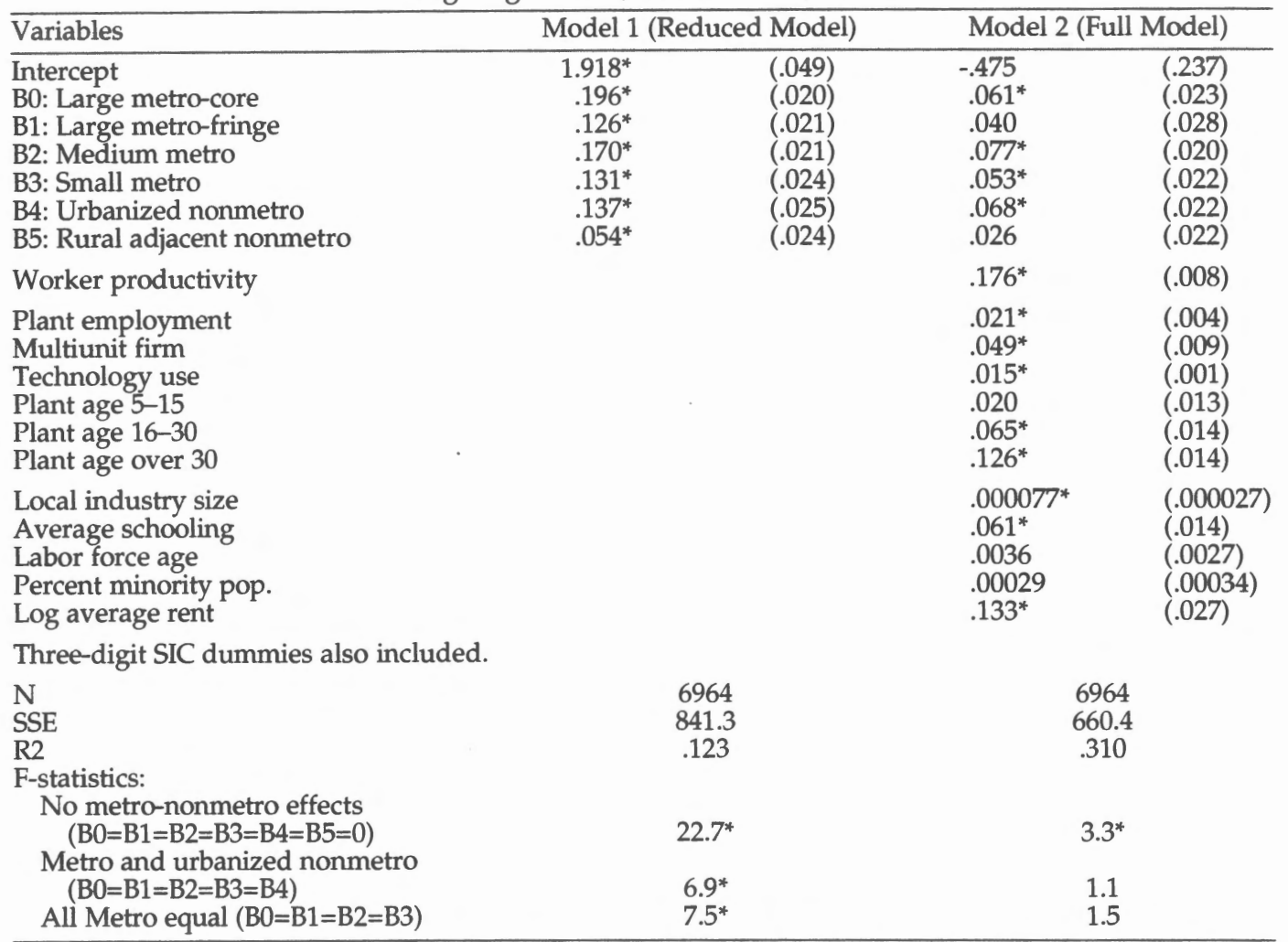

Data are from 1993 Survey of Manufacturing Technology matched with 1992 Census of Manufactures. Dependent variable is log production worker hourly wage. Standard errors in parentheses. Worker productivity is predicted value from three-digit regressions shown in Table 3.

Most of the Beale code coefficients in Model 2 are less than half their magnitudes in the reduced model. Adding productivity, plant, and location characteristics to the model seems to account for a large part of the rural-urban wage differential. When we account for productivity, plant, and location characteristics there is little difference in wages between metro areas of various sizes and urbanized nonmetro counties. The unexplained wage differential is in the most rural locations-those with no town larger than 20,000, especially those not adjacent to a metro area.

I used the production function and wage equation estimates to compute the magnitude of effects of key explanatory variables on wages (Table 5). The mar- 
ginal change in wage was computed using the difference in values shown in the columns labeled "low value" and "high value." (For many of the variables the values correspond to nonmetro and metro averages.) Based on the results shown in Tables 3 and 4 , the effect of a change, $\Delta X_{k}$, in variable $k$ on the wage, $\Delta w$, is computed by $\Delta w=0.176\left(a_{k} \Delta X_{k}\right)+b_{k} \Delta X_{k}$, where $a_{k}$ is the estimated coefficient from the production function and $b_{k}$ is the estimate from the wage equation. Since production coefficients varied across industries, a range of coefficients was used. The third column of Table 5 shows the range of production coefficients used. (No coefficient is shown for variables which did not enter into the production function, i.e., where $a_{k}=0$.) Wage equation coefficients from Table $4, b_{k}$, are shown in the fourth column. The indirect effect on the wage, $0.176\left(\mathrm{a}_{\mathrm{k}} \Delta \mathrm{X}_{\mathrm{k}}\right)$, is shown in the fifth column. The direct effect, $b_{k} \Delta X_{k}$, is shown in the sixth column. $b_{k}$ is not shown when the variable did not enter in the wage equation. The total effect (the sum of indirect and direct effects) is shown in the last column. The range of indirect and total effects corresponds to the range of production function coefficients.

TABLE 5

Marginal wage effects

\begin{tabular}{lrrrrrrrr}
\hline & Low & \multicolumn{2}{c}{ High Prod. fn. } & Wage eqn. & Wage effect: & \\
Variable & value & value & coeff. & coeff. & Indirect ${ }^{1}$ & Direct & Total \\
\hline NPW/PW hour & .157 & .291 & $.2-.6$ & & $.02-.06$ & & $.02-.06$ \\
Machinery/PW hour & 10 & 13 & $0-.15$ & & $0-.007$ & & $0-.007$ \\
Multiplant firm & 0 & 1 & $0-.3$ & .049 & $0-.05$ & .049 & $.049-.099$ \\
Average schooling (years) & 11.5 & 12.0 & $0-.3$ & .061 & $0-.025$ & .031 & $.031-.056$ \\
Housing cost (dollars/month & 300 & 500 & & .133 & & .068 & .068 \\
Plant employment (jobs) & 100 & 500 & & .021 & & .034 & .034 \\
Local industry size (establishments) & 5 & 50 & $0-.004$ & .00007 & $0-.03$ & $0-.003$ & $.003-.033$ \\
\hline
\end{tabular}

${ }^{1}$ Effect of variable on wages through productivity effect.

The low and high values of nonproduction-production labor and machineryproduction labor ratios used to compute marginal effects roughly correspond to metro and nonmetro values. The model results suggest that the higher intensity of nonproduction labor in metro establishments translates to a metro wage premium of 2 to 6 percent for production workers. This is due to the much greater nonproduction worker intensity in metro establishments and the relatively large coefficient on nonproduction worker labor in the production function. The premium due to higher machinery intensity in metro establishments is much smaller, between 0 and 0.7 percent. More intensive use of nonproduction labor in metro plants has a stronger link to the urban wage premium than does capital-intensity.

Plants that are part of multiunit companies are associated with a wage premium of 5 to 10 percent. The estimates showed that workers in multiunit firms had higher productivity in many industries, which can account for a wage premium of 5 percent. The wage equation also suggests a 4.9 percent wage premium associated with multiplant firms apart from the productivity effect. Plant size also can have an important effect on wages. Increasing plant size from 100 to 500 is associated with a 3.4 percent increase in the wage. Consistent with previous research, 
this suggests that larger firms and larger plants pay higher wages. This does not, however, explain rural-urban wage differentials, because rural areas in the sample had larger plants and a higher proportion of plants in multiplant firms.

Lower levels of schooling in rural areas appear to contribute to lower rural earnings. Nonmetro areas had, on average, about 0.5 fewer years of schooling than did metro areas. This difference in schooling is associated with an indirect wage effect of 0 to 2.5 percent and a direct wage effect of about 3 percent. The total effect is comparable in magnitude to the effect of the nonproduction-production labor ratio. Housing cost also may explain an important portion of the rural-urban wage differential. Increasing monthly housing cost from 300 to 500 dollars (which roughly corresponds to a typical rural-urban difference) is associated with an increase in wage of 6.8 percent.

\section{CONCLUSION}

The difference in wages paid by plants in urban and rural areas largely reflects differences in types of manufacturing operations and types of workers. When I control for worker productivity, plant characteristics, and characteristics of the plant's location, there is little or no difference in wages between metro areas of different sizes and urbanized nonmetro counties (with a town of at least 20,000 people). However, a small unexplained differential persists in more rural counties (where fewer than 20,000 people live in urban places) even when the above factors are controlled for.

Much of the rural-urban differential in manufacturing wages may be attributed to the different functions performed by rural and urban plants. More complex, high-value tasks tend to be performed at urban plants, and rural plants tend to engage in more routine batch production. Production workers in urban plants tend to work in plants that have more nonproduction workers than do those in rural plants, an indicator of more skill-intensive activity. In general, U.S. manufacturing has experienced skill-biased technical change (Berman, Bound, and Griliches 1994; Doms, Dunne, and Troske 1997), but the lower share of nonproduction workers at rural establishments indicates that less-skilled routine manufacturing is more common in rural than in urban areas. Rural manufacturing operations apparently have upgraded skills at a slower rate than their urban counterparts.

Lower levels of schooling of the local labor force in rural areas, another indicator of work force skill or quality, also contributes to lower rural earnings through its association with productivity in some industries. This study also finds a positive effect of schooling on production worker wages when productivity is controlled for in the wage equation, suggesting that workers in areas with higher levels of education command higher wages beyond the premium associated with higher productivity. The association between housing costs and wages suggests a compensating differential for higher cost of living in urban areas. The association of wages with local industry size suggests that plants pay a premium for labor in a local market where a particular industry is concentrated. Other labor force char- 
acteristics (age and percent minority population) have no effect on plant-level wages in this study.

Future studies of rural-urban productivity should give attention to the distinction between production-nonproduction labor and analysis by industry. Otherwise, coefficients measuring agglomeration effects may pick up industry and occupational mix effects. Longitudinal establishment data could be employed in future studies of rural-urban productivity and wages to control for unobserved factors which are fixed over time, such as managerial ability or work force quality not captured by other variables (Doms, Dunne, and Troske 1997; Glaeser and Maré 1994).

\section{APPENDIX}

\section{Value Added as a Productivity Measure}

A number of researchers, such as Ciccone and Hall (1996), argue that the census measure of value added cannot be used for geographic comparisons of productivity. They argue that this measure is biased toward showing higher productivity in urban locations because purchased services are excluded from the value added computation. This is due to the assertion that urban establishments purchase more services outside the plant than do establishments in more rural locations who must provide those services internally. Geographic data are not available to test this assertion or to make a correction to the data. However, Gale (1997) used industry-level Census of Manufactures estimates of purchased services to estimate the possible magnitude of the bias. Gale estimated that purchased services were about 1.8 percent of manufacturing value added in 1992 (2 to 4 percent for the industries included in this study). By assuming that all purchased services were bought by metro establishments (i.e., none by nonmetro), Gale estimated that metro average value added per worker would be reduced by $\$ 2000$, which would reduce the metro-nonmetro ratio from 130 to 127 percent. Among the industries included in this study, the ratio was narrowed by 2 to 3 percentage points. This analysis indicates that this bias could only account for a small part of the rural-urban differential in productivity.

\section{REFERENCES}

Barkley, D.L., R.A. Dahlgren, and S.M. Smith. "High Technology in the Nonmetropolitan West: Gold or Just Glitter?" American Journal of Agricultural Economics 70(1988): 560-561.

Berman, E., J. Bound, and Z. Griliches. "Changes in the Demand for Skilled Labor Within U.S. Manufacturing: Evidence from the Annual Survey of Manufactures." Quarterly Journal of Economics 109(May 1994): 367-398.

Bernat, G.A. "Manufacturing Restructuring and Rural Economies: Job Growth But Lagging Wages." Rural Development Perspectives 9(June 1994): 2-8.

"An Update on Rural Manufacturing: Rural Capital Expenditures Lagged Urban in 1992." Rural Development Perspectives 10(Feb. 1995): 15-19. 
Brown, C., and J. Medoff. "The Employer Size-Wage Effect." Journal of Political Economy 97(1989): 1027-1059.

Butler, M.A. Rural-Urban Continuum Codes for Metro and Nonmetro Counties. 1990. Staff Report No. 9028. (Washington, DC: Economic Research Service).

Carlino, G.A. Economies of Scale in Manufacturing Location: Theory and Measurement. 1978. (Leiden: Martinus Nijhoff).

Ciccone, A., and R.E. Hall. "Productivity and the Density of Economic Activity." American Economic Review 86(March 1996): 54-70.

Cochrane, W.G. Sampling Techniques. 1978. (New York: John Wiley \& Sons).

Doms, M., T. Dunne, and K. Troske. "Workers, Wages and Technology." Quarterly Journal of Economics 112(1): 253-90.

Gale, H.F., Jr. "The Rural-Urban Gap in Manufacturing Productivity and Wages: Effects of Industry Mix and Region." 1997. U.S. Dept. Agriculture Staff Paper 9710.

Glaeser, E.L., and D.C. Maré. "Cities and Skills." 1994. NBER working paper No. 4728. (Cambridge, MA: NBER).

Greytak, D., and P. Blackley. "Labor Productivity and Local Industry Size: Further Issues in Assessing Agglomeration Economies." Southern Economic Journal 51(1985): 1121-1129.

Griliches, Z., and V. Ringstad. Economies of Scale and the Form of the Production Function. 1971. (Amsterdam: North Holland Publishing Co.).

Israilevich, P.R., and W.A. Testa. "The Geography of VA." Economic Perspectives (September-October 1989): 2-12.

Little, J.S., and R. Triest. "Technology Diffusion in U.S. Manufacturing: The Geographic Dimension." June 1996. Proceedings of "Technology and Growth" conference, FRB-Boston.

Martin, S.A., R. McHugh, and S.R. Johnson. "The Influence of Location on Productivity: Manufacturing Technology in Rural and Urban Areas." Growth and Change 24(Fall 1993): 459-86.

Moomaw, R.L. "Spatial Productivity Variations in Manufacturing: A Critical Survey of Cross-Sectional Analysis." International Regional Science Review 8(1983): 1-22.

Tolbert, C.A., and M. Sizer. U.S. Commuting Zones and Labor Market Areas. 1996. U.S. Dept. Agriculture Staff Paper 9614.

U.S. Bureau of the Census. Manufacturing Technology: Prevalence and Plans for Use 1993. 1994. SMT(93)-3. (Washington, DC: U.S. GPO).

U.S. Department of Agriculture, Economic Research Service. Rural Conditions and Trends: Rural Industry 7(July 1996). 